\title{
Sirolimus and Hydroxychloroquine as an Add-On to Standard Therapy for Glioblastoma Multiforme: Case Report
}

Mau-Shin Chi ${ }^{1,3}$, Hui-Ling Ko${ }^{1}$, Cheng-Yen Lee ${ }^{1}$, Kai-Lin Yang ${ }^{1}$, Ming-Da Tsai ${ }^{2}$ Kuang-Wen Liao ${ }^{3}$, Ho-Chi Hsu ${ }^{2 *}$ and Kwan-Hwa Chi,5*

${ }^{1}$ Department of Radiation Therapy and Oncology, Shin Kong Wu Ho-Su Memorial Hospital, Taipei, Taiwan

${ }^{2}$ Department of Surgery, Shin Kong Wu Ho-Su Memorial Hospital, Taipei, Taiwan

${ }^{3}$ Institue of Molecular Medicine and Bioengineering, National Chiao-Tung University, Hsinchu, Taiwan

${ }^{4}$ School of Medicine and Institute of Biomedical Imaging and Radiological Sciences, National Yang-Ming University, Taipei, Taiwan

${ }^{5}$ Institute of Veterinary Clinical Science, School of Veterinary Medicine, National Taiwan University, Taiwan

\begin{abstract}
Background: Combined surgery, adjuvant radiotherapy (RT) and temozolomide (TMZ) remain the standard treatment for glioblastoma multiforme (GBM). However, the outcome is grave and novel therapeutic targets are actively researched in translational studies. Double modulation of autophagy by simultaneous administration of the inducer, sirolimus, and the inhibitor, hydroxychloroquine (HCQ) has been applied in clinics and reported to be synergistic as an "autophagy paradox". We describe the first add-on of sirolimus-HCQ to GBM treatment.
\end{abstract}

Patients and methods: We retrospectively enrolled 20 GBM patients who received surgery followed by nonpalliative TMZ and RT therapy in our institute between January 2007 and April 2014. Of these, 3 patients were treated daily with adjunctive HCQ $(400 \mathrm{mg})$ and sirolimus $(2 \mathrm{mg})$ in addition to the standard TMZ-RT treatment.

Results: The median survival time of the 20 patients was 13.7 months (range: 2.2 to 37 months). Surprisingly, the 3 patients who received sirolimus and $\mathrm{HCQ}$ as an add-on treatment survived for a longer period of time (median 34 months). Transient grade 3 myelotoxicity and grade 2 fatigues were rapidly resolved by treatment interruption or dose reduction.

Conclusion: "Autophagy paradox" might be advantageous in combination with standard TMZ-RT treatment for newly diagnosed GBM patients.

Keywords: Radiotherapy; Glioblastoma multiforme; Rapamycin; Hydroxychloroquine; Survival

\section{Introduction}

Glioblastoma multiforme (GBM) is the most aggressive brain tumor. Despite significant advancements in therapy, including surgery, radiotherapy (RT) and chemotherapy, the prognosis of GBM remains poor [1,2]. To control the residual microscopic or macroscopic disease after principal surgery, the standard care comprised RT with concomitant and adjuvant temozolomide (TMZ) [3,4]. However, the median survival of primary GBM was approximately 15 months with $<30 \%$ patients surviving beyond 2 years [3]. The addition of bevacizumab to standard RT-TMZ therapy did not significantly improve the overall survival duration [5,6]. Therefore, an advanced targeting strategy is an urgent prerequisite for GBM treatment.

Autophagy, an evolutionarily conserved response to stress and starvation, is responsible for the degradation of non-functional organelles and proteins [7]. It is a drug resistance mechanism and was found to be cytoprotective against glioma cells [7,8]. Sotelo et al. [9] reported a randomized trial wherein the addition of chloroquine (CQ) to conventional therapy dramatically improved the survival of GBM patients. Although, the exact mechanism was then unknown, CQ is now contemplated as an autophagy inhibitor to prevent the emergence of drug resistance $[7,10]$. An interesting theory of "battery operated tumor growth" proposed that cancer cells induced an autophagy state in the tumor microenvironment leading to the increased production of recycled stromal nutrients to fuel the anabolic and aggressive progression of cancer cells [11,12]. A synergistic association of autophagy inhibitor, CQ, and promoter, sirolimus or rapamycin, was termed as the "autophagy paradox" [13]. This concept was used for clinical varieties of cancer to examine its potential effect on the drug resistance reversal upon sirolimus-hydroxychloroquine (HCQ) add-on to metronomic chemotherapy [14].
Thus far, double modulation of autophagy by simultaneous administration of the autophagy inducer (sirolimus) and autophagy inhibitor (HCQ) with standard TMZ-RT in newly diagnosed GBM patients has not been reported. We hereby describe 3 cases with promising results.

\section{Patients and Methods}

The clinical data of 20 patients pathologically diagnosed with primary GBM and received surgery followed by non-palliative TMZ and RT therapy were assimilated retrospectively from January 2007 to April 2014. This retrospective review was approved by the institute review board. The patients may be treated individually with the related medications, besides TMZ-RT, such as bevacizumab, Rapa and HCQ. All the patients were explained the treatment strategy before obtaining their written consent. Median survival was calculated from the date of surgery and the toxicities were graded according to the common terminology criteria for adverse events version 4.0 (CTCAE v4.0).

*Corresponding authors: Kwan-Hwa Chi, MD, Department of Radiation Therapy and Oncology, Shin Kong Wu Ho-Su Memorial Hospital, Taipei, Taiwan, Tel: +8862-2838-9327; Fax: +886-2-2837-7582; E-mail: M006565@ms.skh.org.tw

Ho-Chi Hsu, MD, Department of Surgery, Shin Kong Wu Ho-Su Memoria Hospital, Taipei, Taiwan, Tel: +886-2-2838-9327; Fax: +886-2-2837-7582; E-mail: M006565@ms.skh.org.tw

Received March 24, 2016; Accepted May 12, 2016; Published May 19, 2016

Citation: Chi MS, Ko HL, Lee CY, Yang KL, Tsai MD, et al. (2016) Sirolimus and Hydroxychloroquine as an Add-On to Standard Therapy for Glioblastoma Multiforme: Case Report. J Biomol Res Ther 5: 141. doi:10.4172/2167-7956.1000141

Copyright: (c) 2016 Chi MS, et al. This is an open-access article distributed unde the terms of the Creative Commons Attribution License, which permits unrestricted use, distribution, and reproduction in any medium, provided the original author and source are credited. 
Citation: Chi MS, Ko HL, Lee CY, Yang KL, Tsai MD, et al. (2016) Sirolimus and Hydroxychloroquine as an Add-On to Standard Therapy for Glioblastoma Multiforme: Case Report. J Biomol Res Ther 5: 141. doi:10.4172/2167-7956.1000141

\section{Results}

Of the 20 patients, 2 received bevacizumab plus TMZ-RT treatment and 3 received sirolimus and HCQ plus TMZ-RT treatment. The median survival of these 20 patients was 13.7 months (ranged over 2.2 to 37 months). Interestingly, the 3 patients receiving sirolimus and HCQ as an add-on treatment exhibited longerl survival (median 34 months) than the other patients. The daily dosage of 1-2 mg sirolimus and 200-400 mg HCQ was considered safe and tolerable based on our previously published results [14]. The clinical treatment is summarized in Table 1.

\section{Case Series}

Case 1: A 71 year old woman presented with headache, dizziness, and progressive decline of cognition and speech for several weeks in 2013. Magnetic resonance imaging (MRI) study showed a right temporal $6.3 \times 4.5 \mathrm{~cm}$ tumors with necrotic changes and peripheral enhancement with marked vasogenic edema. Tumor resection was performed in 2013/01 and histopathologic examination confirmed GBM. Post-operative computed tomography (CT) scan showed residual enhancement over tumor bed. The patient was prescribed daily oral 2 $\mathrm{mg}$ sirolimus and $400 \mathrm{mg}$ HCQ as an add-on treatment to the standard TMZ-RT treatment for one year. TMZ was prescribed at a daily dosage of $75 \mathrm{mg} / \mathrm{m}^{2}$ during RT and $150 \mathrm{mg} / \mathrm{m}^{2}$ on days $1-5$ of 28 day cycle after RT. The clinical targeted volume-high $(\mathrm{CTVH})$ and clinical targeted volume-medium (CTVM) were $5940 \mathrm{cGy} / 27 \mathrm{fx}$ and $4860 \mathrm{cGy} / 27 \mathrm{fx}$, respectively. The TMZ dosage was reduced to $240 \mathrm{mg} /$ day for 4 days every month with half dosage of sirolimus $(1 \mathrm{mg})$ and HCQ $(200 \mathrm{mg})$ for the following treatment cycles owing to grade 3 myelotoxicity after the second cycle of adjuvant chemotherapy. The treatment lasted for an additional 18 months without notable side effects. Brain MRI findings were followed regularly. She was capable of performing daily activities under assistance without evidence of recurrent disease for more than 3 years until now (Figures 1A and 1B).

Case 2: A 62 year old woman presented at the emergency department with weakness in her left extremities for $2 \mathrm{~h}$ in 2013/04. The symptom was preceded with dizziness and headache on the same day. Glasgow coma scale (GCS) was E4V5M6. The brain CT showed intracranial hemorrhage over right occipital lobe, which necessitated an emergent decompression surgery. Intraoperatively, a brain tumor was seen apart from the obvious hemorrhage. Postoperative MRI showed a cystic tumor with hyperintense $\mathrm{T} 2$ and hypointense T1 signals with heterogeneous contrast enhancement. The pathological report was consistent with GBM. The patient was prescribed $2 \mathrm{mg}$ sirolimus and $400 \mathrm{mg}$ HCQ per day as an add-on to the TMZ-RT treatment. The doses prescribed for CTVH and CTVM were $6600 \mathrm{cGy} / 33 \mathrm{fx}$ and $5000 \mathrm{cGy} / 25 \mathrm{fx}$, respectively. TMZ was prescribed at a dosage of 75 $\mathrm{mg} / \mathrm{m}^{2}$ daily during radiotherapy period, followed by another 6 cycles of adjuvant TMZ at a fixed dose of $150 \mathrm{mg} / \mathrm{m}^{2}$ on days1-5 every 28 days. Maintenance daily dose of $200 \mathrm{mg}$ HCQ and $1 \mathrm{mg}$ sirolimus was continued for another 1 year. There was neither >grade 2 toxicities nor treatment delay in the whole therapy course. Brain images were followed at 3 month intervals. There was no radiographic evidence of disease recurrence for nearly 3 years (Figures 2A and 2B).

Case 3: A 69 year old man presented with progressive weakness of left limbs. The brain MRI showed right temporal lobe tumor, measuring 5.3 $\times 4.7 \times 4.6 \mathrm{~cm}$ with necrosis and prominent vasogenic edema. A partial resection was performed in 2013/06. Vascular endothelial proliferation with tumor necrosis and GBM were confirmed pathologically. $\mathrm{He}$ was treated with TMZ-RT coupled with daily administration of $2 \mathrm{mg}$ sirolimus and $400 \mathrm{mg}$ HCQ for 2 weeks. Then, dosage was reduced by $50 \%$ to $1 \mathrm{mg}$ sirolimus and $200 \mathrm{mg}$ HCQ daily for another 7 months due to grade 2 fatigue. Dosages prescribed for CTVH and CTVM were $6000 \mathrm{cGy} / 30 \mathrm{fx}$ and $5000 \mathrm{cGy} / 25 \mathrm{fx}$, respectively. Concomitant TMZ was prescribed as $75 \mathrm{mg} / \mathrm{m}^{2}$ continually during radiotherapy and followed by 6 cycles of adjuvant TMZ at $150 \mathrm{mg} / \mathrm{m}^{2}$ on days $1-5$ of 28 day cycle. MRI showed recurrent GBM 18 months after surgery. Owing to the high risk of repeated surgery and re-irradiation, bevacizumab was used as salvage therapy. The patient survived for an additional 10 months.

\section{Discussion}

We have applied the autophagy paradox theory to the treatment of clinical varieties of cancers [14], including these 3 cases. The TMZRT treatment caused DNA damage and rendered GBM into a high stress condition [15]. Stress induced autophagy acts as one of the drug

\begin{tabular}{|c|c|c|c|c|}
\hline & & Patient 1 & Patient 2 & Patient 3 \\
\hline \multirow[b]{3}{*}{$\begin{array}{l}\text { Concurrent } \\
\text { TMZ-RT phase }\end{array}$} & RT & $5940 \mathrm{cGy} / 27 \mathrm{fx}$ & $\begin{array}{c}6600 \mathrm{cGy} / 33 \\
\mathrm{fx}\end{array}$ & $\begin{array}{c}6000 \mathrm{cGy} / 30 \\
\mathrm{fx}\end{array}$ \\
\hline & TMZ & $\begin{array}{c}75 \mathrm{mg} / \mathrm{m}^{2} \mathrm{QD} \\
\text { during } \mathrm{RT}\end{array}$ & $\begin{array}{c}75 \mathrm{mg} / \mathrm{m}^{2} \mathrm{QD} \\
\text { during } \mathrm{RT}\end{array}$ & $\begin{array}{c}75 \mathrm{mg} / \mathrm{m}^{2} \mathrm{QD} \\
\text { during } \mathrm{RT}\end{array}$ \\
\hline & Sirolimus/HCQ & $\begin{array}{c}\text { Sirolimus: } 2 \\
\text { mg QD } \\
\text { HCQ: } 400 \mathrm{mg} \\
\text { QD }\end{array}$ & $\begin{array}{c}\text { Sirolimus: } 2 \\
\text { mg QD } \\
\text { HCQ: } 400 \mathrm{mg} \\
\text { QD }\end{array}$ & $\begin{array}{c}\text { Sirolimus: } 2 \\
\text { mg QD, HCQ: } \\
400 \text { mg QD } \\
\text { for } 2 \text { weeks } \\
\text { then reduce } \\
\text { dose to } \\
\text { sirolimus } 1 \mathrm{mg} \\
\text { QD, HCQ } \\
200 \text { mg QD } \\
\text { for another } 4 \\
\text { weeks }\end{array}$ \\
\hline \multirow[b]{2}{*}{ Adjuvant phase } & TMZ & $\begin{array}{c}150 \mathrm{mg} / \mathrm{m}^{2} \\
\text { on D1-D5 of } \\
28 \text { days for } 6 \\
\text { cycles }\end{array}$ & $\begin{array}{c}150 \mathrm{mg} / \mathrm{m}^{2} \\
\text { on D1-D5 of } \\
28 \text { days for } 6 \\
\text { cycles }\end{array}$ & $\begin{array}{c}150 \mathrm{mg} / \mathrm{m}^{2} \\
\text { on D1-D5 of } \\
28 \text { days for } 6 \\
\text { cycles }\end{array}$ \\
\hline & Sirolimus/HCQ & $\begin{array}{c}\text { Sirolimus: } 2 \\
\text { mg QD, HCQ: } \\
400 \text { mg QD for } \\
2 \text { cycles then } \\
\text { reduced to } \\
\text { sirolimus } 1 \mathrm{mg} \\
\text { QD and HCQ } \\
200 \text { mg QD } \\
\text { for another } 4 \\
\text { cycles }\end{array}$ & $\begin{array}{c}\text { Sirolimus: } 2 \\
\text { mg QD } \\
\text { HCQ: } 400 \\
\text { mg QD for } 6 \\
\text { cycles }\end{array}$ & $\begin{array}{l}\text { Sirolimus: } 1 \\
\text { mg QD } \\
\text { HCQ: } 200 \\
\text { mg QD for } 6 \\
\text { cycles }\end{array}$ \\
\hline $\begin{array}{l}\text { Maintenance } \\
\text { phase }\end{array}$ & Sirolimus/HCQ & $\begin{array}{c}\text { Sirolimus: } 1 \\
\text { mg QD } \\
\text { HCQ: } 200 \\
\text { mg QD for } 18 \\
\text { months }\end{array}$ & $\begin{array}{c}\text { Sirolimus: } 1 \\
\text { mg QD } \\
\text { HCQ: } 200 \\
\text { mg QD for } 12 \\
\text { months }\end{array}$ & $\begin{array}{l}\text { Sirolimus: } 1 \\
\text { mg QD } \\
\text { HCQ: } 200 \\
\text { mg QD for } 1 \\
\text { month }\end{array}$ \\
\hline
\end{tabular}

Table 1: Dose and schedule summary of the 3 cases.

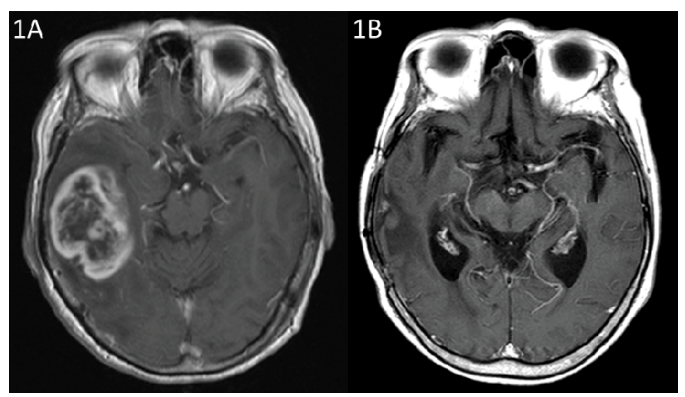

Figure 1: (A) Pre-operative MRI showed right temporal lobe mass in 2013/01. GBM was confirmed. (B) Follow-up MRI in 2015/07. No evidence of recurrence. 
Citation: Chi MS, Ko HL, Lee CY, Yang KL, Tsai MD, et al. (2016) Sirolimus and Hydroxychloroquine as an Add-On to Standard Therapy for Glioblastoma Multiforme: Case Report. J Biomol Res Ther 5: 141. doi:10.4172/2167-7956.1000141

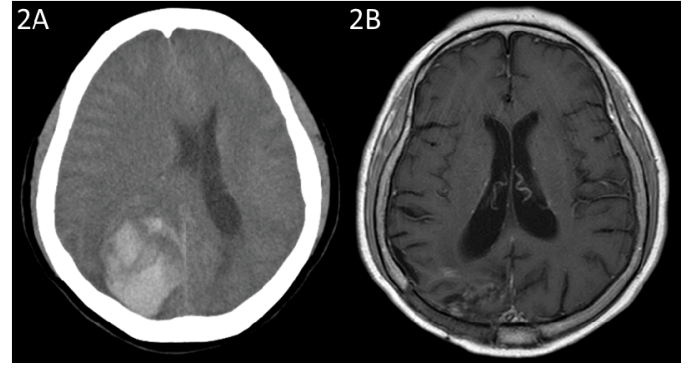

Figure 2: (A) Pre-operative CT showed right occipital lobe tumor with hemorrhage in 2013/04. GBM was confirmed. (B) Follow-up MRI in 2015/10, No evidence of recurrence.

resistance mechanisms [7]. However, the role of autophagy in GBM pathogenesis remains controversial. A high expression level of pivotal autophagy genes, LC3 and Beclin1 correlates with improved survival; while high-grade GBM presents with low autophagy activity [16]. This suggests a growth inhibitory effect of autophagy in high-grade glioma.

TMZ utilizes autophagy to induce cell death in glioma-derived cell lines [17]. Sirolimus inhibits glioma cell line proliferation in vitro and tumor growth in mouse xenograft model by inducing autophagy [18]. Several studies on GBM cell lines suggested that: 1) mTOR signaling is frequently hyper-activated in GBM [19]; 2) Sirolimus increased and maintained the level of autophagy flux [20]; 3) Sirolimus inhibits the growth of GBM [18]. Phase 1 clinical trial of $10 \mathrm{mg}$ sirolimus daily in GBM patients with PTEN (phosphatase and tension homolog deleted on chromosome 10) deficiencies for one week showed anti-proliferative effect and enhanced penetration to the blood brain barrier (BBB) [21]. Although both TMZ and sirolimus induce high autophagy activity, a recently published phase II trial failed to show the benefit of adding everolimus, a sirolimus analog, to the standard TMZ-based treatment [22], indicating that autophagy activation alone was not effective in reversing the drug resistance of GBM.

Another approach by which autophagy inhibitors, CQ or HCQ have been reported to reverse the drug resistance in glioma cells lines is as follows [23]. HCQ potentiated the inhibitory effect of radiation on cancer cell proliferation through negative regulation of DNA repair process [24]. A study on human GBM cell lines showed that HCQ affects the cellular redox state by depleting glutathione [25,26]. HCQ has also been reported to cross the BBB [27]. The striking median survival of 24 months vs. 11 months with CQ plus radiotherapy-lomustine as observed in a randomized clinical trial in newly diagnosed GBM patients was very intriguing [9]. Another recent phase I/II trial of hydroxychloroquine (HCQ) in conjunction with RT-TMZ protocol in GBM patients indicated that $600 \mathrm{mg}$ daily is the maximal tolerated dose [28]. Sirolimus along with TMZ maintained the cells in high autophagy state while HCQ blocked the final autophagosome formation that burdened the mitochondrial stress resulting in apoptotic cell death [29].

The maximal tolerated daily dose of everolimus with standard RTTMZ was reported as $10 \mathrm{mg}$ in a phase I study [30]. Moreover, the reduced dosage was expected to be less than $5 \mathrm{mg}$ if coupled with HCQ. A common long-term maintenance dose for transplantation recipients is $2 \mathrm{mg}$ sirolimus $2 \mathrm{mg}$, which is about $3-5 \mathrm{mg}$ of everolimus [31,32].

No improvement in the outcome documented since the introduction of RT-TMZ therapy in 2005 was observed. The phase III randomized trials testing the addition of bevacizumab to standard RTTMZ treatment for newly diagnosed GBM did not report an increase in the overall survival duration $[5,6]$. To the best of our knowledge, there was no reported drug interaction between TMZ, sirolimus, and HCQ. Transient grade 3 myelotoxicity and grade 2 fatigues were observed. However, these could be rapidly resolved by the short treatment interruption and dose reduction. The toxicity of 3 drug combination was well tolerable in the dose range of 1-2 mg sirolimus and 200-400 mg HCQ for 8-18 months of daily treatment. The recommended dosage would begin with $2 \mathrm{mg}$ sirolimus and $400 \mathrm{mg}$ HCQ per day for a period of 18 months while allowing the dose modification as an adjunctive treatment to TMZ-RT. An official clinical trial will be launched.

\section{Acknowledgement}

A part of the data in the study was based on the Cancer Registry Database of Cancer Center, Shin Kong Wu Ho-Su Memorial Hospital.

\section{Conflict of Interest}

On behalf of all the authors, the corresponding author states that there is no conflict of interest.

\section{References}

1. Louis DN, Ohgaki H, Wiestler OD, Cavenee WK, Burger PC, et al. (2007) The 2007 WHO classification of tumours of the central nervous system. Acta Neuropathol 114: 97-109.

2. Darefsky AS, King JT Jr, Dubrow R (2012) Adult glioblastoma multiforme survival in the temozolomide era: a population-based analysis of Surveillance, Epidemiology, and End Results registries. Cancer 118: 2163-2172.

3. Keime-Guibert F, Chinot O, Taillandier L, Cartalat-Carel S, Frenay M, et al (2007) Radiotherapy for glioblastoma in the elderly. N Engl J Med 356:15271535.

4. Mirimanoff RO, Gorlia T, Mason W, Van den Bent MJ, Kortmann RD, et al (2006) Radiotherapy and temozolomide for newly diagnosed glioblastoma recursive partitioning analysis of the EORTC 26981/22981-NCIC CE3 phase III randomized trial. J Clin Oncol 24: 2563-2569.

5. Gilbert MR, Dignam JJ, Armstrong TS, Wefel JS, Blumenthal DT, et al. (2014) A randomized trial of bevacizumab for newly diagnosed glioblastoma. N Engl J Med 370: 699-708.

6. Chinot OL, Wick W, Mason W, Henriksson R, Saran F, et al. (2014) Bevacizumab plus radiotherapy-temozolomide for newly diagnosed glioblastoma. $\mathrm{N}$ Engl J Med 370: 709-722.

7. Sui X, Chen R, Wang Z, Huang Z, Kong N, et al. (2013) Autophagy and chemotherapy resistance: a promising therapeutic target for cancer treatment. Cell Death Dis 4: e838.

8. Lefranc F, Kiss R (2006) Autophagy, the Trojan horse to combat glioblastomas Neurosurg Focus 20: E7.

9. Sotelo J, Briceno E, Lopez-Gonzalez MA (2006) Adding chloroquine to conventional treatment for glioblastoma multiforme: a randomized, doubleblind, placebo-controlled trial. Ann Intern Med 144: 337-343.

10. Duffy A, Le J, Sausville E, Emadi A (2015) Autophagy modulation: a target fo cancer treatment development. Cancer Chemother Pharmacol 75: 439-447.

11. Bonuccelli G, Tsirigos A, Whitaker-Menezes D, Pavlides S, Pestell RG, et al. (2010) Ketones and lactate "fuel" tumor growth and metastasis: Evidence that epithelial cancer cells use oxidative mitochondrial metabolism. Cell Cycle 9 : 3506-3514.

12. Martinez-Outschoorn UE, Balliet RM, Rivadeneira DB, Chiavarina B, Pavlides $\mathrm{S}$, et al. (2010) Oxidative stress in cancer associated fibroblasts drives tumorstroma co-evolution: A new paradigm for understanding tumor metabolism, the field effect and genomic instability in cancer cells. Cell Cycle 9: 3256-3276.

13. Martinez-Outschoorn UE, Whitaker-Menezes D, Pavlides S, Chiavarina B Bonuccelli G, et al. (2010) The autophagic tumor stroma model of cancer or "battery-operated tumor growth": a simple solution to the autophagy paradox. Cell Cycle 9: 4297-4306.

14. Chi KH, Ko HL, Yang KL, Lee CY, Chi MS, et al. (2015) Addition of rapamycin and hydroxychloroquine to metronomic chemotherapy as a second line treatmen results in high salvage rates for refractory metastatic solid tumors: a pilot safety and effectiveness analysis in a small patient cohort. Oncotarget 6: 16735-16745. 
Citation: Chi MS, Ko HL, Lee CY, Yang KL, Tsai MD, et al. (2016) Sirolimus and Hydroxychloroquine as an Add-On to Standard Therapy for Glioblastoma Multiforme: Case Report. J Biomol Res Ther 5: 141. doi:10.4172/2167-7956.1000141

15. Combs SE, Schmid TE, Vaupel P, Multhoff G (2016) Stress response leading to resistance in glioblastoma-the need for innovative radiotherapy (irt) concepts. Cancers (Basel) 8: 15.

16. Kaza N, Kohli L, Roth KA (2011) Autophagy in brain tumors: a new target for therapeutic intervention. Brain Pathol 22: 89-98.

17. Kanzawa T, Germano IM, Komata T, Ito H, Kondo Y, et al. (2004) Role of autophagy in temozolomide-induced cytotoxicity for malignant glioma cells. Cell Death Differ 11: 448-457.

18. Arcella A, Biagioni F, Antonietta Oliva M, Bucci D, Frati A, et al. (2012) Rapamycin inhibits the growth of glioblastoma. Brain Res 1495: 37-51.

19. Bouchard F, Belanger SD, Biron-Pain K, St-Pierre Y (2012) EGR-1 activation by EGF inhibits MMP-9 expression and lymphoma growth. Blood 116: 759-766

20. Eisenberg-Lerner A, Kimchi A (2009) The paradox of autophagy and its implication in cancer etiology and therapy. Apoptosis 14: 376-391.

21. Cloughesy TF, Yoshimoto K, Nghiemphu P, Brown K, Dang J, et al. (2008) Antitumor activity of rapamycin in a Phase I trial for patients with recurrent PTEN-deficient glioblastoma. PLoS Med 5: e8.

22. Ma DJ, Galanis E, Anderson SK, Schiff D, Kaufmann TJ, et al. (2014) A phase II trial of everolimus, temozolomide, and radiotherapy in patients with newly diagnosed glioblastoma: NCCTG N057K. Neuro Oncol 17: 1261-1269.

23. Geng Y, Kohli L, Klocke BJ, Roth KA (2010) Chloroquine-induced autophagic vacuole accumulation and cell death in glioma cells is $\mathrm{p}^{53}$ independent. Neuro Oncol 12: 473-481.

24. Pazmino NH, Yuhas JM (1974) Chloroquine: nonselective inhibition of recovery from radiation injury in tumors and normal tissues. Radiat Res 60: 54-61.
25. Briceno E, Reyes S, Sotelo J (2003) Therapy of glioblastoma multiforme improved by the antimutagenic chloroquine. Neurosurg Focus 14: e3.

26. Park BC, Park SH, Paek SH, Park SY, Kwak MK, et al. (2008) Chloroquineinduced nitric oxide increase and cell death is dependent on cellular GSH depletion in A172 human glioblastoma cells. Toxicol Lett 178: 52-60.

27. Adelusi SA, Salako LA (1982) Tissue and blood concentrations of chloroquine following chronic administration in the rat. J Pharm Pharmacol 34: 733-735.

28. Rosenfeld MR, Ye X, Supko JG, Desideri S, Grossman SA, et al. (2014) A phase $\mathrm{I} / \mathrm{II}$ trial of hydroxychloroquine in conjunction with radiation therapy and concurrent and adjuvant temozolomide in patients with newly diagnosed glioblastoma multiforme. Autophagy 10: 1359-1368.

29. Li C, Liu Y, Liu H, Zhang W, Shen C, et al. (2015) Impact of autophagy inhibition at different stages on cytotoxic effect of autophagy inducer in glioblastoma cells. Cell Physiol Biochem 35: 1303-1316.

30. Chinnaiyan P, Won M, Wen PY, Rojiani AM, Wendland M, et al. (2013) RTOG 0913: a phase 1 study of daily everolimus (RAD001) in combination with radiation therapy and temozolomide in patients with newly diagnosed glioblastoma. Int J Radiat Oncol Biol Phys 86: 880-884.

31. Sato E, Yano I, Shimomura M, Masuda S, Katsura T, et al. (2009) Larger dosage required for everolimus than sirolimus to maintain same blood concentration in two pancreatic islet transplant patients with tacrolimus. Drug Metab Pharmacokinet 24: 175-179.

32. Carvalho C, Coentrao L, Bustorff M, Patricio E, Sampaio S, et al. (2011) Conversion from sirolimus to everolimus in kidney transplant recipients receiving a calcineurin-free regimen. Clin Transplant 25: E401-E405. 